\title{
Clinico- Epidemiological Characteristics of Benign Breast Disease
}

\author{
Sapna Purushotham ${ }^{1}$, Krishna Kumar T K \\ ${ }^{1}$ Associate Professor, Department of Surgery, East Point College of Medical Sciences, Bangalore, Karnataka, ${ }^{2}$ Assistant Professor, Department of Surgery, \\ East Point College of Medical Sciences, Bangalore, Karnataka.
}

\section{Abstract}

Background: The diagnostic accuracy of FNA biopsy of breast masses approximates $80 \%$. When the specimen is properly prepared and reviewed by an experienced cytopathologist, the false-positive result is rare. False-negative results occur in approximately $15 \%$ of cases and thus a lesion that is suspicious clinically or by imaging must be further investigated with core biopsy or surgical excision. Subjects and Methods: About 50 cases of benign breast diseases were selected, only inpatient cases are considered for the study. Outpatient cases, males, malignant cases and cases which were operated early were excluded from the study. Results: Majority of our patients (92\%) were in the premenopausal period. Average age of menarche in this group was 13.33 years. $62 \%$ of the patients belong to the age group of $12-13$ years.46(50) of our patients were married. Out of these 42, breast fed their babies for a period of 1 year. 7 out of 50 of our patients had more than one child and breast fed their babies for a period of 3- 5 years. Conclusion: 54\% of the patients presented with complaints of right breast and $30 \%$ with complaints of left breast and only $16 \%$ with complaints in both breast.

Keywords: Benign Breast disease, pre- menopausal period, FNA biopsy.

Corresponding Author: Dr. Krishna Kumar T K, Assistant Professor, Department of Surgery, East Point College of Medical Sciences, Bangalore, Karnataka.

Received: December 2019

Accepted: December 2019

\section{Introduction}

In both men and women, the borders of the breast extend vertically from the second rib superiorly to the sixth rib inferiorly and horizontally from lateral border of sternum medially to the midaxillary line laterally. A thin layer of breast tissue may extend beyond these limits upto clavicle superiorly, rectus muscle inferiorly and midsternum medially.

Breast being a modified sweat gland in the dermis, lies entirely in superficial fascia, condensed bands of which extend from deep fascia below to the skin above and form the suspensory ligaments of Cooper (Cooper ligaments named in honor of Sir Astley Cooper, who advanced understanding of breast anatomy in his 1840 book on breast anatomy). ${ }^{[1]}$

The deep parenchymal tissues of the breast are enveloped by both an anterior and posterior facial layer. Most of the breast overlies the pectoralis major muscle covered with deep fascia (pectoral fascia), extending over serratus anterior muscle laterally, and upper abdominal oblique muscles inferiorly. The breast is separated from the pectoral fascia by a loose areolar tissue, called the retromammary space which is responsible for free mobility of normal breast over pectoralismajor. A small lateral extension of breast extends towards axilla pierces deep fascia and dips into axilla. This is called axillary tail of spence, the only small part of breast below deep fascia. ${ }^{[2]}$

The most common causes of nipple discharge in the nonlactating breast: duct ectasia, intraductal papilloma, and carcinoma.Bloody discharge is suggestive of malignancy but is more often caused by a benign papilloma in the duct. Seen more likely in women over age 50 years. ${ }^{[3]}$

In premenopausal women, spontaneous multiple duct discharge, unilateral or bilateral, most noticeable just before menstruation, is often due to fibrocystic condition. Discharge may be green or brownish. Papillomatosis and ductal ectasia are usually detected only by biopsy.

A milky discharge from multiple ducts in the nonlactating breast may occur from hyperprolactinemia. Serum prolactin levels should be obtained to search for a pituitary tumor. Thyroid-stimulating hormone (TSH) to exclude hypothyroidism. Numerous antipsychotic drugs, oral contraceptive agents or estrogen replacement therapy may cause clear, serous, or milky discharge from a single or multiple ducts. ${ }^{[4]}$

A purulent discharge may originate in a subareolar abscess and require removal of the abscess and the related lactiferous sinus.

When localization is not possible, no mass is palpable, and the discharge is non bloody, the patient should be reexamined every 3 or 4 months for a year, and a mammogram and an ultrasound should be performed. Cytologic examination of the nipple discharge for exfoliated 
cancer cells is rarely helpful in determining a diagnosis. To eliminate the discharge, proximal duct excision can be performed both for treatment and diagnosis.Cytologic analysis of a solid mass by fine needle aspiration (FNA) biopsy can be obtained rapidly, and often the patient can be informed of the results the same day. The technique can be performed using imaging guidance or by palpation. ${ }^{[5]}$

The diagnostic accuracy of FNA biopsy of breast masses approximates $80 \%$. When the specimen is properly prepared and reviewed by an experienced cytopathologist, the falsepositive result is rare. False-negative results occur in approximately $15 \%$ of cases and thus a lesion that is suspicious clinically or by imaging must be further investigated with core biopsy or surgical excision. When physical examination, imaging, and FNA yield benign concordant results, the probability of a lesion being benign approaches $95 \% .^{[6]}$

After taking history. General physical examination along with blood pressure and pulse should be checked. Benign disorders are rarely associated with loss of weight or anemia. Head to toe examination should be done.

Usually normal breast should be examined first. Proper exposure of both the breasts from neck to waist should be done. Sitting posture gives good information regarding level of nipples, a lump and palpation of axilla in doubt bending down will help in giving more information regarding retraction of nipples. Recumbent position helps to palpate lump against the chest wall.

\section{Subjects and Methods}

About 50 cases of benign breast diseases were selected, only inpatient cases are considered for the study. Outpatient cases, males, malignant cases and cases which were operated early were excluded from the study.

Detailed history of all the fifty cases were taken according to the proforma approved by the guide. Information regarding age, religion, socio- economic status, nature of symptoms, duration, menstrual status, marital status, breast feeding were taken. History regarding to the usage of oral contraceptive pills, built and nourishment, habits were also noted. Family history regarding any breast conditions were obtained.

All the patients were examined systematically including breast examination and systematic examination and assessment of nutritional status. All underwent routine investigations which included blood counts- $\mathrm{Hb} \%, \mathrm{BT}, \mathrm{CT}$, Blood sugar levels(RBS), Blood urea, Serum creatinine, Urine routine and ECG. Investigations like USG and Mammography were done in some number of required cases. The follow- up of the prospective cases were done at the hospital in OPDs. About 28 cases returned to the hospital for follow- up most of them being outpatients treated conservatively and some who were operated. The period of follow- up ranged from 3- 18 months with mean of 8 months depending upon the time of entry into the study. The follow up included recording of the patients symptoms. At the end of the study period and follow- up the material was analyzed and results were tabulated.

\section{Result}

In this study 47 patients were Hindus, while only 3 patients were Muslims. Distribution along the line of history cannot be done due to small number of cases.

Table 1: Age Distribution based on religion

\begin{tabular}{|l|l|l|}
\hline Religion & No. of patients & \% \\
\hline Hindu & 47 & 94.0 \\
\hline Muslim & 3 & 6.0 \\
\hline Total & 50 & 100.0 \\
\hline
\end{tabular}

$54 \%$ of the patients presented with complaints of right breast and $30 \%$ with complaints of left breast and only $16 \%$ with complaints in bothbreast.

Table 2: Side of disease

\begin{tabular}{|l|l|l|}
\hline Location & No. of patients & \% \\
\hline Right & 27 & 54.0 \\
\hline Left & 15 & 30.0 \\
\hline Bilateral & 8 & 16.0 \\
\hline Total & 50 & 100.0 \\
\hline
\end{tabular}

Table 3: Menstrual History

\begin{tabular}{|l|l|l|}
\hline Menstrual History & No. of patients & \% \\
\hline Post- menopausal & 4 & 8.0 \\
\hline Pre- menopausal & 46 & 92.0 \\
\hline Total & 50 & 100.0 \\
\hline
\end{tabular}

Majority of our patients (92\%) were in the pre- menopausal period.

Average age of menarche in this group was 13.33 years. $62 \%$ of the patients belong to the age group of $12-13$ years.

Table 4: Age of Menarche

\begin{tabular}{|l|l|l|}
\hline Age of Menarche & No. of patients & \% \\
\hline 12 & 19 & 38.0 \\
\hline 13 & 12 & 24.0 \\
\hline 14 & 17 & 34.0 \\
\hline 15 & 2 & 4.0 \\
\hline Total & 50 & 100.0 \\
\hline
\end{tabular}

Table 5: Marital Status
\begin{tabular}{|l|l|l|}
\hline Marital Status & No. of patients & $\%$ \\
\hline Married & 46 & 92.0 \\
\hline Unmarried & 4 & 8.0 \\
\hline Total & 50 & 100.0 \\
\hline
\end{tabular}

History of use of oral contraceptive pills was obtained only with 4 patients.

\begin{tabular}{l}
\hline Table 6: Use of Oral contraceptives \\
\begin{tabular}{|l|l|l|}
\hline Use of Oral contraceptives & No. of patients & $\%$ \\
\hline Negative & 46 & 92.0 \\
\hline Positive & 4 & 8.0 \\
\hline Total & 50 & 100.0 \\
\hline
\end{tabular}
\end{tabular}

46(50) of our patients were married. Out of these 42, breast fed their babies for a period of 1 year. 7 out of 50 of our patients had more than one child and breast fed their babies for a period of 3- 5 years. 
Table 7: Breast feeding

\begin{tabular}{|l|l|l|}
\hline Breast Feeding & No. of patients $(\mathbf{n}=\mathbf{5 0})$ & $\mathbf{\%}$ \\
\hline No & 8 & 16.0 \\
\hline Yes & 42 & 84.0 \\
\hline $1-2$ & 35 & 70.0 \\
\hline $3-5$ & 7 & 14.0 \\
\hline
\end{tabular}

2 out of 50 of our patients had earlier undergone conservative treatment for mastitis and developed antibioma for which they reported to us with persistent complaints of fever, pain and lumpiness in the breast.

Table 8: Past History

\begin{tabular}{|l|l|l|}
\hline Past History & No. of patients & \% \\
\hline Negative & 48 & 96.0 \\
\hline Positive & 2 & 4.0 \\
\hline Total & 50 & 100.0 \\
\hline
\end{tabular}

\section{Discussion}

In the Edwin Smiths surgical papyrus, the earliest known medical record (3000-5000 BC) description on bulging tumours of the breast that were differentiated from abscesses and mastitis are noted.

Recognition of differentiation of benign tumours from malignant tumours began in the $16^{\text {th }}$ century. Severance in 1632 in the book "Strumas of Ovary" distinguished clinically the benign and malignant tumours for the first time.

John Hunter(1728-1793) described fibroadenoma as a tumour, which occurred at the age of 26 years in a woman and increased gradually to 38 years of age.

AstleyPastonCooper(1768-1841)surgeon, Guy"s Hospital, London, England was an important early worker to describe many aspects of benign breast disorders as well as malignant disease, in his monograph- "Illustration of diseases of the breast", published in 1829.7

Benjamin Collins Brodie(1783-1862) Surgeon, St. Georgees Hospital, London, England, described cystosarcomaphylloides (Serocystic disease of Brodie) in $1840 . .^{88]}$

German surgeon Schimmelbusch discussed about cystic disease of the breast in $1890^{\text {ec }} \mathrm{s}$.

The French surgeon, Reclus, gave an excellent description of clinical and pathological aspects of cystic diseases in 1893, recognizing both multiplicity and bilaterality of the cysts. ${ }^{[7]}$ Dupont and Page performed the classic study on the relationship between benign breast disease and subsequent development of carcinoma. They followed more than 3000 women for at least 15 yrs. after breast biopsy. The study population was divided into three groups according to histology of the original biopsy. The first group about $70 \%$ with no proliferative changes, only adenosis, apocrine metaplasia, ductectasia, epithelial hyperplasia developed carcinoma in $2 \%$ over $15 \mathrm{yr}$ period. The second group $26 \%$ with epithelial hyperplasia but no cellular atypia developed carcinoma in $4 \%$ (relative risk 1.6 times). The third group $4 \%$ with atypical ductal or lobular hyperplasia developed carcinoma in $8 \%$ (relative risk 5 times) over 15 years period. ${ }^{[9]}$

Dr. Uma Krishnaswamy (2003), Department of Surgery Apollo Hospitals, Chennai in his cross sectional analysis of
1786 Urban Indian Woman undergoing routine health check-up found that $12.75 \%$ women had benign breast problems. ${ }^{[10]}$

A prospective Cohort study by Tariq WahabKhanzada et al at Isra University Hospital, Hyderabad and two other private hospitals in Hyderabad, Pakistan showed that Fibroadenoma was the most common benign breast disease seen in $27 \%$ of patients followed by fibrocystic disease in $21 \%$. The conclusion was that benign breast diseases are common problems in females of reproductive age. Fibroadenoma is the commonest and mostly seen in $2^{\text {nd }}$ and $3^{\text {rd }}$ decades of life. Fibrocystic disease is the next common BBD whose incidence increases with increasing age. ${ }^{[1]}$

A study of breast lump of 2246 cases by fine needle aspiration by Dr. Pradhan M, Pathology clinic, Oslo, Norway between 2000-2004 found that out of 2246 cases, 1840 cases were non-malignant out of which $47 \%$ was fibrocystic, $8 \%$ fibroadenoma, $6 \%$ abscess. ${ }^{[12]}$

A study by Tewari $M$ et al, Department of Surgical Oncology, Institute of Medical Sciences, Varanasi (2005) found that the significance of breast tuberculosis is due to the mistaken identity with breast cancer and pyogenic breast abscess. Diagnosis isbased on identification of typical histological features of tuberculosis, cytology and culture. ${ }^{[13]}$ A study of profile of Breast lesions among women with positive biopsy findings by A.K. Al Thobhani et al (2006), Department of Surgery, University of Sana"s, Yemen showed that benign lesions were found in $79.9 \%$ of cases and Invasive Carcinoma in $20.1 \%$ of cases. Fibroadenoma was the most prevalent lesion(30\%) with mean age of presentation of 22.2 years, followed by fibrocystic disease $(27.4 \%)$ and breast inflammation(13.1\%). ${ }^{[14]}$

In 2009, Engwad et al studied 783 aspirates to determine whether FNAC or CNB should be used as the first preoperative diagnostic tool and recommended the use of FNAC as a first choice tool in triple diagnostics.

Clinicopathalogical study of benign breast diseases conducted among 489 cases of breast lesions in SBHGM college Maharashtra in 2011, found benign breast disease in $79 \%$ with fibroadenoma the commonest and fibrocystic disease the next commonest.

A three year study of breast lesions in women aged 15-70 years was conducted in a tertiary care hospital in SKIMS, Srinagar (J \& K)(2014). Among 72 cases $77.77 \%$ were benign and $22.22 \%$ were malignant lesions of breast.

\section{Conclusion}

$54 \%$ of the patients presented with complaints of right breast and 30\% with complaints of left breast and only $16 \%$ with complaints in both breast.

\section{References}

1. Frank T. Padberg "Classification and Clinical and Diagnostic Evaluation of patients with Chronic venous disorders." In Rutherfold vascular text book.chapter 155.6th edition: W.B. Sounders company;2005: 2232-2235.

2. Peter J.pappas,Brajesh K. Lal "The Pathophysiology of chronic venous insufficiency" in Vascular surgery by Rutherford RB, 4thEdn. Vol II, W.B. Sounders company;2005: 2220-2227.

3. Rhoda MacKenzie and Andrew W. Bradbury "Chronic Venous 
Insufficiency" in Essential surgical practice, Module 35, 4th edition, 2002 Hodder Arnold Publications.891-923.

4. Das S, "Examination of Varicose Veins", in Clinical Das. SB publications, Ch.10; Edn.4th: 1998: 73-79.

5. Michaels JA, Brazier JE, Campbell WB, et al. (2005) Randomized clinical trial comparing surgery with conservative treatment for uncomplicated varicose veins. Br J Surg 93:175-181.

6. De Medeiros CA, Luccas GC (2005) Comparison of endovenous treatment with an $810 \mathrm{~nm}$ laser versus conventional stripping of the great saphenous vein in patients with primary varicose veins. DermatolSurg 31(12):1685-1694.

7. Bergan J, Pascarella L, Mekenas L (2006) Venous disorders: treatment with sclerosant foam. J CardiovascSurg (Torino) 47(1):918.

8. Schouten R, Mollen RM, Kuijpers HC (2006) A comparison between cryosurgery and conventional stripping in varicose vein surgery: perioperative features and complications. Ann VascSurg 20(3):306-
311.

9. nSybrandy JE, Wittens CHA (2002) Initial experience in endovenous treatment of saphenous vein reflux. J VascSurg 36:1207- 1212

10. Babcock WW (1907) A new operation for the extirpation of varicose veins of the leg. N Y Med J 86:153-156.

11. Nisar A, Shabbir J, Tubassam MA, et al. (2006) Local anaesthetic flush reduces postoperative pain and haematoma formation after great saphenous vein stripping-a randomised controlled trial. Eur J VascEndovascSurg 31(3):325-331.

12. Winterborn RJ, Earnshaw JJ (2006) Crossectomy and great saphenous vein stripping. J CardiovascSurg (Torino) 47(1):19-33.

13. Holme JB, Skajaa K, Holme K (1990) Incidence of lesions of the saphenous nerve after partial or complete stripping of the long saphenous vein. ActaChirScand 156(2):145-148.

14. Ramasastry SS, Dick GO, Futrell JW (1987) Anatomy of the saphenous nerve: relevance to saphenous vein stripping. Am Surg 53(5):274-277.

Copyright: () the author(s), 2019. It is an open-access article distributed under the terms of the Creative Commons Attribution License (CC BY 4.0), which permits authors to retain ownership of the copyright for their content, and allow anyone to download, reuse, reprint, modify, distribute and/or copy the content as long as the original authors and source are cited.

How to cite this article: Purushotham S, Kumar KTK. Clinico- Epidemiological Characteristics of Benign Breast Disease. Acad. J Surg. 2019;2(2):55-58.

DOI: dx.doi.org/10.21276/ajs.2019.2.2.15

Source of Support: Nil, Conflict of Interest: None declared. 